\title{
A Spatio-Temporal Analysis of Mitochondrial DNA Haplogroup I
}

\author{
Peter Z. Revesz $z^{1, a}$ \\ ${ }^{1}$ Department of Computer Science, University of Nebraska-Lincoln, Lincoln, NE, 68588, USA
}

\begin{abstract}
The recent recovery of ancient DNA from a growing number of human samples shows that mitochondrial DNA haplogroup I was introduced to Europe after the end of the Last Glacial Maximum. This paper provides a spatio-temporal analysis of the various subhaplogroups of mitochondrial DNA I. The study suggests that haplogroup I diversified into haplogroups I1, I2'3, I4 and I5 at specific regions in Eurasia and then spread southward to Crete and Egypt.
\end{abstract}

\section{Introduction}

Ancient mitochondrial DNA (mtDNA) provides important insights on the movement and spread of human populations out of Africa. In particular, European populations exhibit some remarkable changes after the end of the Last Glacial Maximum. The changes in the early postglacial period are thought to be the result of the arrival of new human population groups to Europe. These new populations brought to Europe the I and W mitochondrial DNAs [6]. The origin and exact spread of these two mitochondrial DNAs is little understood. This paper provides a spatio-temporal analysis of mtDNA I.

This paper is organized as follows. Section 2 presents some related work. Section 3 describes the source data and our data curating to refine and improve the haplogroup classifications and find the precise latitude and longitude coordinates of the location where each sample was discovered. Section 4 describes our spatiotemporal analysis of the curated data. Finally Section 5 gives some conclusions and directions for future work.

\section{Related work}

Several papers have attempted to trace the movement and spread of human populations based on ancient DNA data. Allentoft et al. [1] considers Eurasian populations and traces of Indo-European migrations in the Bronze Age. Other papers have made DNA-based connections between past and present day populations, such Brandt et al. [3] between ancient DNA and present Central Europeans and Vai et al. [14] between Medieval Lombards and present day Italians.

The difficulty of making connections between pairs of populations lies in the fact that most human populations are genetically fairly mixed, making the comparison of populations rely on complex statistical similarities according to several proposals including a

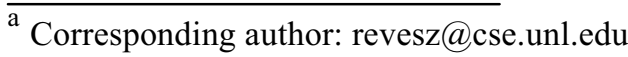

recent one by the author [11]. For example, modern European human populations in every region contain a large number of mitochondrial DNA haplogroups. In contrast, Paleolithic human samples contain only a limited number of mtDNA haplogroups, mostly belonging to $U$. The genetics of European Neolithic human populations is relatively well-studied and traced back to Anatolia and the Near East [2], [4], [5]. However, mtDNA haplogroup I is associated neither with the Paleolithic nor with the Neolithic expansion. Hervella et al. [6] show that mtDNA haplogroup I occurs in Paternanbidea, Spain c. between 6000 BC. This early presence in Spain suggests that mtDNA I expanded to Eurasia from the Franco-Cantabrian glacial refugium after the Last Glacial Maximum. However, Olivieri et al. [8] argue that mtDNA haplogroup I originates from the Near East. That discrepancy and the uncertainty regarding the origin of the subhaplogroups of haplogroup I motivates the present study.

\section{Source data and data curation}

Several websites are specialized to record ancient mitochondrial DNA samples. Below we used the ancestral journals online database and website, which is available at the following Internet site: http://www.ancestraljourneys.org/ancientdna.shtml.

Table 1 lists from thirteen cultures fourteen samples that can be classified into one of the mtDNA haplogroups I1, I2, I3, I4 and I5. The Unetice culture had both I1 and I3 samples. For each of the sample locations, we found its latitude and longitude using Google map.

Some of the samples were classified as simply mtDNA I, but we could use the latest version of the mtDNA haplogroup classification table (Build 17, February 18, 2016) at www.PhyloTree.org to further refine the classification to I1, I2, I3, I4 or I5 haplogroup. 
Table 1. Cultures that contain mitochondrial DNA I1, I2, I3, I4 or I5 samples.

\begin{tabular}{|l|l|r|l|c|c|}
\hline Type & \multicolumn{1}{|c|}{ Culture } & \multicolumn{1}{c|}{ Date } & \multicolumn{1}{c|}{ Place } & Latitude & Longitude \\
\hline Neolithic & $\begin{array}{l}\text { Cami de Can Grau } \\
\text { Granollers }\end{array}$ & $3500-3000$ BC & $\begin{array}{l}\text { Cami de Can Grau Granollers, } \\
\text { Barcelona, Spain }\end{array}$ & 41.43 & 2.12 \\
\hline Bronze & Yamnaya & $3000-2500$ BC & Kirovohrad, Ukraine & 48.30 & 32.16 \\
\hline Bronze & Bell Beaker & $2600-2500$ BC & Kromsdorf, Germany & 50.98 & 11.37 \\
\hline Bronze & Minoan & $2200-1700$ BC & Charalambos cave, Crete, Greece & 35.18 & 25.44 \\
\hline Bronze & Unetice & $2200-1550$ BC & Eulau, Germany & 51.17 & 11.85 \\
\hline Bronze & Unetice & $2200-1550$ BC & Esperstedt, Germany & 51.42 & 11.67 \\
\hline Bronze & Mezhovskaya & $1598-1398$ BC & Kapova cave, Russia & 53.04 & 57.06 \\
\hline Bronze & Karasuk & $1416-1268$ BC & Sabinka, near Karasuk, Russia & 53.43 & 78.03 \\
\hline Bronze & Vodokhranilische & $1400-1000$ BC & Vodokhranilische, Kazakhstan & 49.52 & 49.86 \\
\hline Iron & Norabak & $1209-1009$ BC & Norabak, Armenia & 40.13 & 45.86 \\
\hline Iron & Scythian & $500-200$ BC & Rostov-on-Don, Russia & 47.14 & 39.42 \\
\hline Iron & Egyptian & $402-385$ BC & Faiyum Valley, Egypt & 29.57 & 30.66 \\
\hline Medieval & Lombard & $570-650$ AD & Collegno, Italy & 45.50 & 7.35 \\
\hline Medieval & Hungarian & $975-1000$ AD & Sárrétudvar, Hungary & 47.25 & 21.17 \\
\hline
\end{tabular}

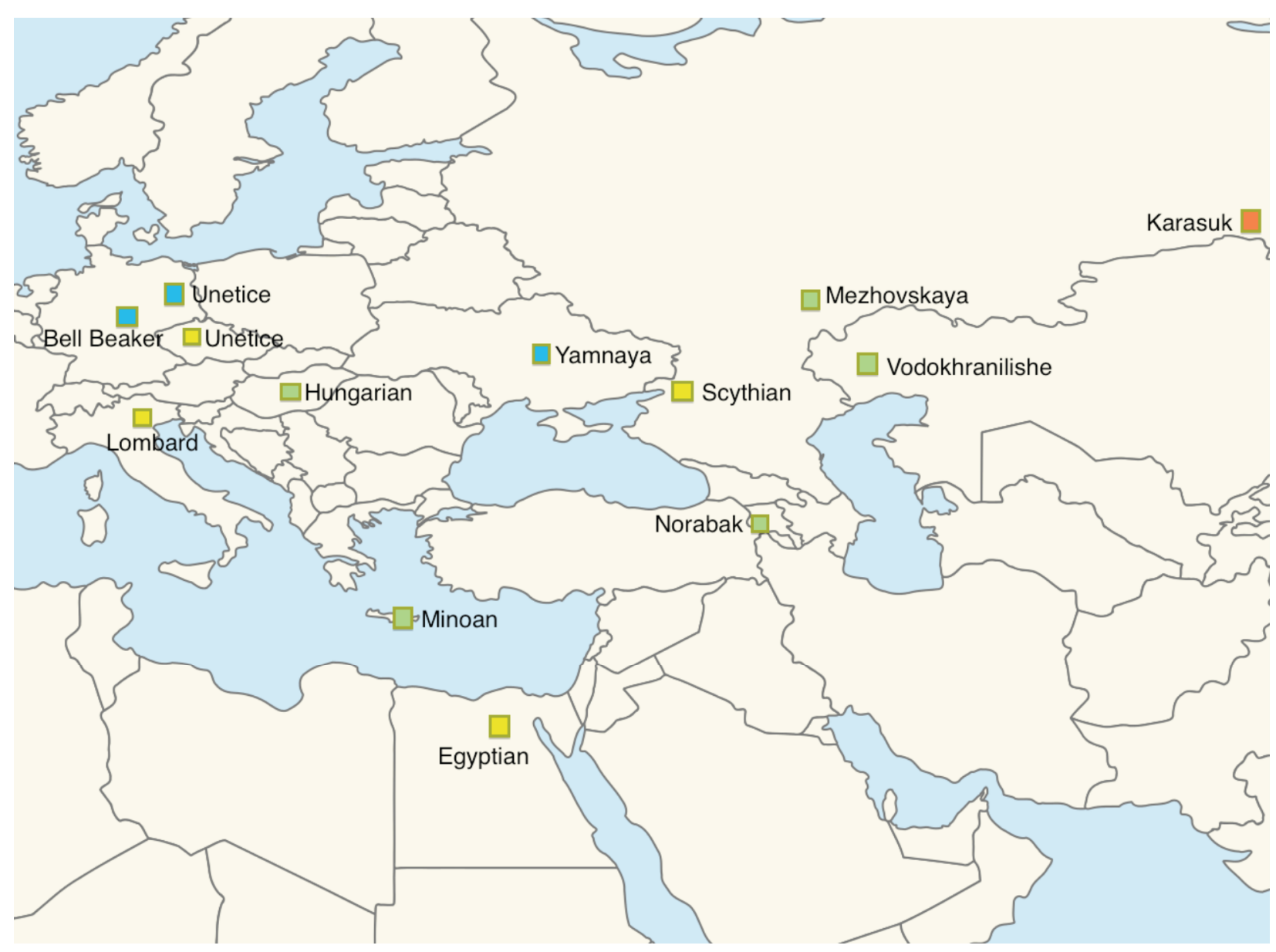

Figure 1. The distribution of mtDNA haplogroup samples I1 (blue), I2 and I3 (yellow), I4 (red) and I5 (green). 
Table 2. Ancient DNA samples that belong to some branch of mtDNA haplogroup I. The samples and their classifications are from the website http://www.ancestraljourneys.org/ancientdna.shtml. Some of the classifications are updated. In case of

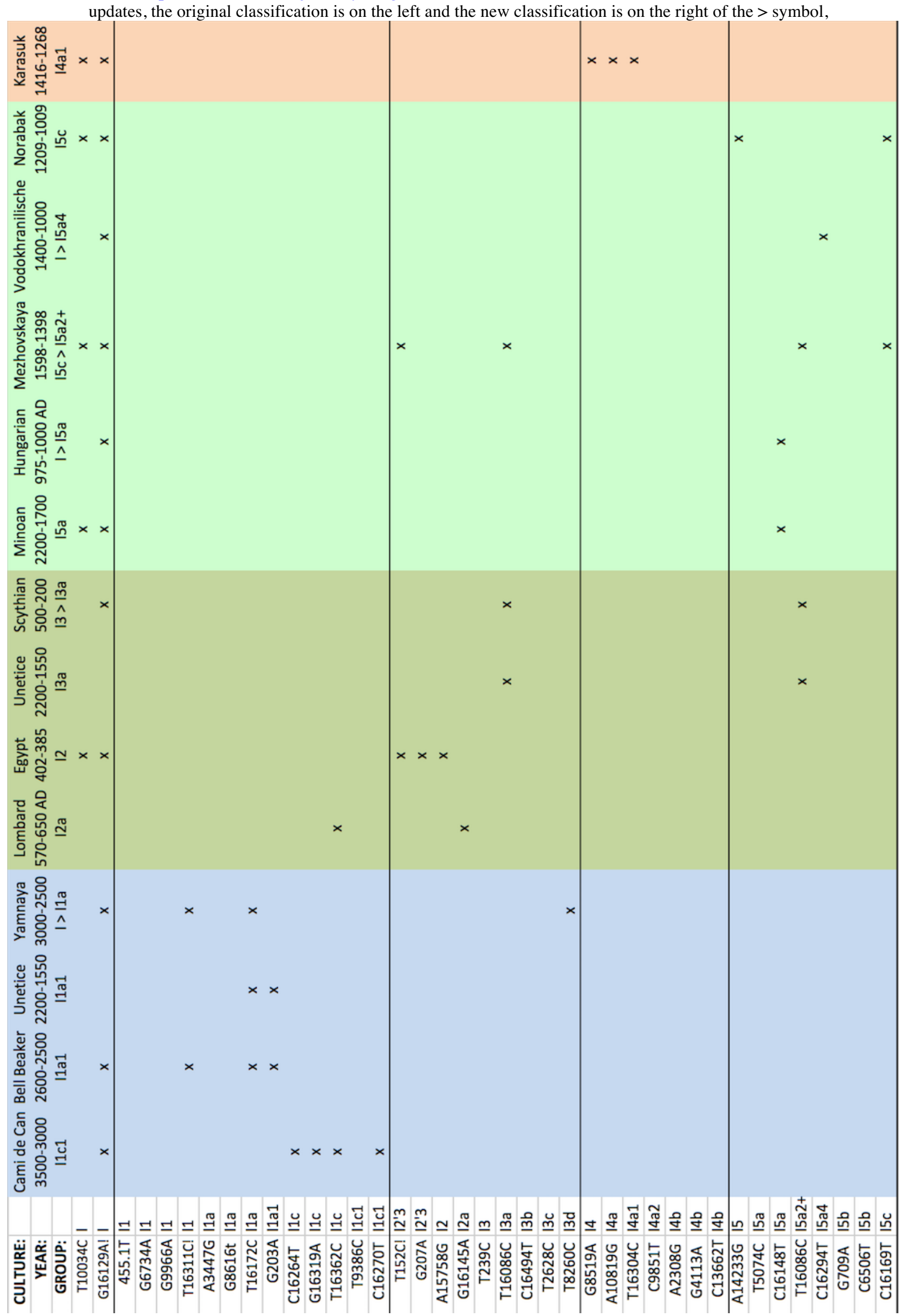


In particular, we improved the classification of one Yamnaya sample from I to I1a, one Vodokhranilische sample from I to I5a4, and one Hungarian sample from I to I5a. In addition, we could refine the classification of a Scythian I3 sample to I3a. Table 2 gives a detailed explanation of the reason for these refinements. As Table 2 shows, there are still some ambiguities regarding the classification of a few samples. For example, the Mezhovskaya sample can be considered either I5c or I5a2 as shown in Table 2. The ancestral journeys online database contains some other mtDNA I samples that could not be further refined, including currently the earliest mtDNA haplogroup I sample from Paternanbidea, Spain from the Neolithic [6].

In Table 2 the first four data columns contain I1 samples, the next four contain I 2 and I 3 samples, the next five contain I5 samples, and the last contains a single I4 sample. The I 2 and I3 haplogroups have a common ancestor called mtDNA I2'3. Therefore, in this paper we consider them as one group. We color-coded the haplogroups as blue for I1, golden for I2 and I3, green for I5, and red for I4. Using a similar color scheme, Figure 1 shows the location of each sample on a map.

\section{Spatio-temporal analysis}

At first we computed the centroid of each haplogroup. The result is shown in Table 3 .

Table 3. The haplogroup centroid values.

\begin{tabular}{|l|l|l|}
\hline Haplogroup & Latitude & Longitude \\
\hline I1 & 47.97 & 14.375 \\
\hline I2’3 & 43.4075 & 22.275 \\
\hline I4 & 53.43 & 78.03 \\
\hline I5 & 45.024 & 39.878 \\
\hline
\end{tabular}

The data in Table 3 needs to be considered together with the map in Figure 1. In combination, they allow us to draw some conclusions regarding the origin of the various haplogroups in this study. In particular the map suggest the following:

I1: This haplogroup is more western (with longitude 14.375) than other haplogroups and also more northern (47.97) than other haplogroups except for I4. Hence it is likely that this haplogroup originated in northwestern Europe.

I2'3: This haplogroup occurs in an old Unetice sample and three considerably more recent samples near the shores of the Mediterranean and Black Seas. Hence it is likely that this group also originated in northern Eurasia and the three later samples are the result of population movements facilitated by the seas.

I4: This haplogroup occurs only in one sample, which happens to be the easternmost of all the samples. Hence it is likely that this haplogroup originates somewhere in central Eurasia.
I5: This haplogroup seems to be concentrated between and above the Black and the Caspian Seas. Hence that area is the likely origin of haplogroup I5. The presence of haplogroup I5 in some Minoan samples may be explained as a population movement from the Black Sea to Crete. The Hungarian sample may be explained as another population movement from the region north of the Black Sea to present day Hungary.

Overall, the ancient mtDNA data suggests that the origin of the I1, I2'3, I4 and I5 haplogroups are all connected with various regions in Europe and western Asia.

\section{Conclusions and future work}

The spatio-temporal analysis of this paper can be extended in many ways using the methods described in [9]. In particular, we are interested in modeling the spread of human populations as spatio-temporal objects that are described using constraint databases [7]. This may be further combined with an extension of phylogenetic tree algorithms, such as the Common Mutations Similarity Matrix algorithm [10] and the Incremental Phylogenetics by Repeated Insertions algorithm [12]. Finally, the rate of evolution of the various subhaplogroups of mtDNA $I$ is another interesting topic to be further explored perhaps by applying techniques similar to those in the study of bacterial evolution [13].

The extended study could also benefit from other ancient mtDNA I samples that may become available in the near future. The study of ancient human DNA is an exciting area of research, and in that study mtDNA haplogroup I plays an interesting role as a testimony to the earliest meeting of Paleolithic survivors in glacial refugia and newcomers to the European continent from either North Africa or the Near East.

\section{References}

1. M. Allentoft et al., Nature, 522, 167-172 (11 June 2015)

2. R. Bollongino, O. Nehlich, M.P. Richards, J. Orschiedt, M.G. Thomas, C. Sell, Z. Fajkošová, A. Powell, J. Burger, Science, 342, 6157, 479-481 (25 Oct. 2013)

3. G. Brandt et al., Science, 342, 6155, 257-261 (2013).

4. P. Brotherton, Nature Comm., 4, Art. No. 1764 (2013)

5. W. Haak, et al., PloS Bio., 8, 11, (November 2010)

6. M. Hervella et al., Arch. and Anthrop. Sciences, 8, 1, 97-106 (March 2016)

7. P.C. Kanellakis, G.M. Kuper, P.Z. Revesz, J. of Comp. and Sys. Sciences, 51, 1, 26-52 (1995)

8. A. Olivieri, M. Pala, F. Gandini, B.H. Kashani, U.A. Perego, S.R. Woodward, V. Grugni, V. Battaglia, O. Semino, A. Achilli, M.B. Richards, A. Torroni, PLoS ONE, 8, 7, (2013) 
9. P.Z. Revesz, Introduction to Databases: From Biological to Spatio-Temporal, (Springer, New York, 2010)

10. P.Z. Revesz, Proc. 4th ACM Int. Conf. on Bioinfo. and Comp. Bio., 731-734, (ACM Press, New York, USA, 2013)

11. P.Z. Revesz, Int. J. of Bio. and Biomed. Eng., 10, 1, 124-133 (2016)

12. P.Z. Revesz and Z. Li, Int. J. of Bio. and Biomed. Eng., 10, 1, 148-158 (2016)

13. M. Shortridge, T. Triplet, P.Z. Revesz, M. Griep, R. Powers, Comp. Bio. and Chem., 35, 1, 24-33, (2011)

14. S. Vai et al., PLoS ONE 10, 1, (2015) 